\title{
Sosyoekonomik şartların diş hekimliği öğrencilerinin ağız sağlığına olan etkisi: Anket çalışması
}

\author{
Yener Okutan ${ }^{\alpha}$, Mustafa Borga Dönmez ${ }^{\beta}$, Münir Tolga Yücel ${ }^{\beta}$
}

Selcuk Dent J, 2017; 4: 59-67 (Doi: 10.15311/1441.302076)

Başvuru Tarihi: 10 Nisan 2017 Yayına Kabul Tarihi: 01 Haziran 2017

\section{öz}

Sosyoekonomik şartların diş hekimliği öğrencilerinin ağız sağlığına olan etkisi: Anket çalışması

Amaç: Kesitsel tipteki bu çalıșmanın amacı, dişhekimliği öğrencilerinin sosyoekonomik statülerinin ağız sağlıklarına olan etkisini araştırmaktır.

Gereç ve Yöntemler: Selçuk Üniversitesi Diş Hekimliği Fakültesi'nde öğrenim gören toplam 173 ikinci ve üçüncü sınıf öğrencisi arasında kapsamlı bir sosyal, kültürel ve dișhekimliği değerlendirme anketi hazırlanmış ve dağıtımıştır. Oral sağlık durumu, ağız hijyeni bilgisi, protetik restorasyon prevalansı, öğrencilerin sosyal ve ekonomik durumu değerlendirilmiştir. Kasaba ve ilçelerdeki öğrencilerin restorasyon prevalansı şehirlerden gelen öğrencilerin restorasyon prevelansı ile karşılaştırımıştır. Anket, sabit protez, implant destekli restorasyonlar, laminate veneerler, inley-onley restorasyonlar ve gece plakları gibi değişik protetik tedavileri türlerini içermektedir. Dolgu ile restore edilmiş dişler ve eksik dişler de değerlendirilmiştir. Son olarak, çalışmanın verileri Pearson KiKare testi kullanılarak analiz edilmiştir.

Bulgular: Elde edilen sonuçlara göre sadece 11 öğrencinin protetik restorasyonu bulunmaktadır. 117 öğrencinin dișlerinde dolgu tespit edilmiştir. Ailelerinin gelirleri yüksek olan veya üniversiteden önceki yașantısını şehirde sürdüren öğrencilerin dolgu sıklığı daha düşük olarak bulunmuştur. Buna ek olarak, 67 öğrencide dişhekimi korkusu olduğu tespit edilmiştir.

Sonuç: Ağız sağlığı birçok faktörün etkisi altındadır. Bu çalışmanın sonuçlarına dayanarak sosyoekonomik durumun diş hekimliği öğrencilerinin ağız sağı̆ğı üzerinde düşük bir etkisi olabileceği sonucuna varılabilir.

\section{ANAHTAR KELIMELER}

Ağız sağlığı, diş hekimliği öğrencileri, protetik restorasyon

Ağız sağlığının korunmasının temelinde iyi bir ağız hijyeni gelmektedir. ${ }^{1}$ İyi bir ağız hijyeni hayat kalitesinin artmasında temel faktörlerden biri olarak kabul edilmektedir. Ağız sağlığı sadece lokalize bir kavram olmamakla birlikte, aynı zamanda kardiyovasküler hastalık, diabetes mellitus, kronik solunum yolu hastalığı ve romatoid artrit gibi çeşitli sistemik hastalıklarla da önemli ölçüde ilişkilidir.2, 3

\section{ABSTRACT}

The effect of socioeconomic conditions on oral health status of dentistry students: A questionarrie based study

Background: The aim of this cross-sectional study was to investigate the effect of social status on oral health between dental students.

Methods: A comprehensive social, cultural and dental assessment questionnaire was designed and distributed among 173 second and third grade students of Selcuk University Faculty of Dentistry. Oral health status, oral hygiene knowledge, prosthetic restoration prevalence, social and economic conditions of students were evaluated. Restoration prevalence of students from towns and districts was compared with the students from cities. The questionnaire contained different types of prosthetic treatments such as fixed partial denture, implant supported restorations, laminate veneers, inlay-onlay restorations and night guards. Restored teeth with filling materials and the missing teeth were also evaluated. Finally, data of the study were evaluated using Pearson Chi-Square test

Results: According to the results, only 11 students had a prosthetic restoration. Restored teeth with a filling material were detected in 117 students. Students, whose families had high incomes or who lived in the city before university had a lower prevalence of filling. Additionally, 67 students were detected with a dental anxiety.

Conclusion: Oral health is affected by many factors. Based on the results of this study it can be concluded that socioeconomic condition may have a slight effect on oral health of dentistry students.

\section{KEYWORDS}

Oral health, dentistry students, prosthetic rehabilitation

Sağlık konusu ele alındığında, yaşam tarzııın, sosyoekonomik ve çevresel faktörlerin ciddi etkilerinin olduğu açıkça görülmektedir. Bu faktörler arasında sosyoekonomik etkenler önemli bir yer teşkil etmektedir., 5 Bir bireyin sosyoekonomik statüsü arttıkça veya sosyal seviyenin en üstüne çıkıldıkça daha sağlıklı olduğu bildirilmiştir. ${ }^{6}$ Uluslararası düzeyde bakıldığında ise daha varlıklı ülkelerin daha yoksul ülkelerle karşılaştııılığında daha iyi sağlık sonuçlarına

\footnotetext{
${ }^{\alpha}$ Adnan Menderes Üniversitesi Diş Hekimliği Fakültesi Protetik Diş Tedavisi Anabilim Dalı, Aydın

$\beta$ Selçuk Üniversitesi Diş Hekimliği Fakültesi Protetik Diş Tedavisi Anabilim Dalı, Konya
} 
sahip olduğu belirtilmiştir. ${ }^{7}$ Geçmiş yıllarda yapılan çalışmalar, sosyoekonomik faktörlerin ağız sağığı üzerinde etkileri olduğunu ortaya koymuştur. ${ }^{8}$ Ayrıca diș temizliği, profesyonel mekanik diș temizleme ${ }^{9}$ ve diyet şekerleri' ${ }^{10}$ gibi bireysel faktörlerin de ağız sağlığıyla ilişkili olabileceği ve hem yaşam biçimi hem de sosyoekonomik koşullarla ilişkili olabileceği rapor edilmiştir. ${ }^{9}$ Üniversite öğrencileri arasında yapılan çalışmalar incelendiğinde günde iki kereden az diş fırçalama alışkanlığının, düşük ve orta gelir düzeyine sahip ülke öğrencilerinde (ör. Hindistan'da $\% 52,2^{11}$, Lübnan'da $\% 35^{12}$, Türkiye'de $\% 32^{13}$ ) yüksek gelirli ülkelerdeki öğrencilere göre (İtalya'da \%7,9 ${ }^{14}$, ABD'de $\% 25^{15}$ ) daha fazla olduğu görülmektedir. Benzer şekilde, üniversite öğrencileri arasında yıllık dişhekimliği kontrollerinin yılda birden daha az görülme oranının, gelişmekte olan ülkelerde (Kenya'da $\% 84^{16}$, Nijerya'da \%92, $2^{17}$, Türkiye'de $\% 70^{13}$; Hindistan'da $\% 42,7^{11}$ ve İran'da $\% 48,2{ }^{\prime} \mathrm{si}^{18}$ ise hiç diş hekimini ziyaret etmemiştir) endüstriyel ülkelerden (Finlandiya'da $\% 41^{19}$, İtalya'da $\% 40,1^{14}$ ) daha yüksek olduğu bulunmuştur. Bu çalışmanın amacı, sosyoekonomik düzeyleri farklı olan dişhekimliği öğrencilerinin ağız sağlıklarının karşılaştırımasıdır. Çalışmanın hipotezi sosyoekonomik düzeyi yüksek olan öğrencilerin ağız sağlığının, sosyoekonomik düzeyi düşük olan öğrencilere göre daha iyi olacağıdır.

\section{GEREÇ VE YÖNTEM}

Selçuk Üniversitesi Diş Hekimliği Fakültesi'nde eğitim görmekte olan toplamda 173 ikinci ve üçüncü sınıf öğrencisi gönüllü olarak bu çalışmaya katılmıştır. Katıımcıların doldurmaları için kapsamlı bir sosyal, kültürel ve ağız sağlığı değerlendirme anketi tasarlanmıştır (Şekil 1). Hazırlanan anket ile öğrencilerin ağız sağlıklarının durumu, ağız hijyeni bilgileri, protetik restorasyon prevalansları, sosyal ve ekonomik durumları değerlendirilmiştir. Ankette öğrencileri sosyodemografik özelliklerine göre (yaş, cinsiyet, ikamet yeri, ebeveynlerin eğitim durumu ve mezun olunan okul) sınıflayabilmek adına sorular bulunmaktadır. Öğrencilerin ağız hijyeni alışkanlıkları diş fırçalama sıklıkları ve dişipi veya ara yüz fırçası kullanımları üzerinden değerlendirilmiştir. Ağız sağığı ve hijyenini direkt olarak etkileyebilecek olan sigara kullanımı ve asitli içecek tüketim sıklığı anket kapsamı içinde yer almaktadır. Aynı zamanda katıımcıların hem dental anksiyeteleri hem de diş hekimine gitme sıklıkları sorgulanmıştır. Anketin protetik restorasyonlar ile ilgili olan soruları, sabit protez, implant destekli restorasyonlar, laminate veneerler, inley-onley restorasyonlar ve gece plağı gibi değişik protetik tedavileri türlerinin prevelansını sorgulamıştır. Ayrıca restoratif materyallerle tedavi edilmiş dişler ve eksik dişler de değerlendirilmiştir. Elde edilen veriler Pearson Ki-Kare testi kullanılarak analiz edilmiştir (Tablo 1).

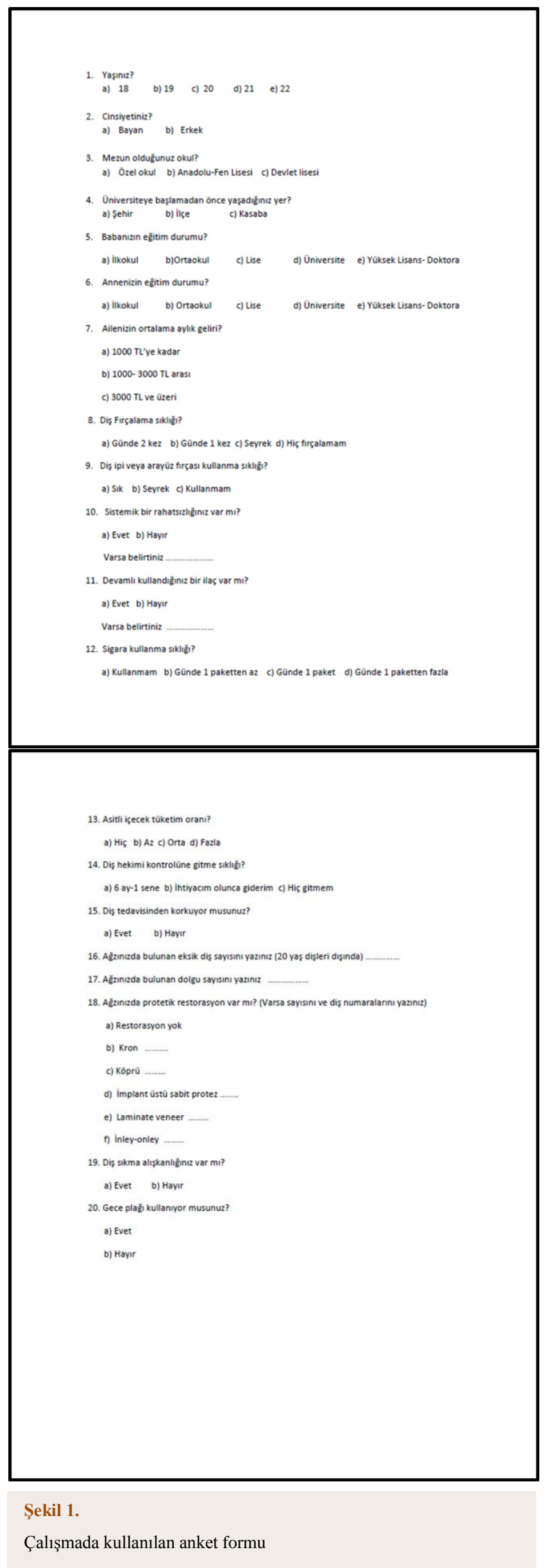


Tablo 1.

\section{İstatiksel analiz sonuçları}

\begin{tabular}{|lcc|} 
& Pearson ki-kare & p \\
\hline Protetik Restorasyon - Aylık Gelir & 0,015 & 1 \\
\hline $\begin{array}{l}\text { Protetik Restorasyon - } \\
\text { Anne Eğitim Durumu }\end{array}$ & 0,432 & 0,454 \\
\hline $\begin{array}{l}\text { Protetik Restorasyon - } \\
\text { Baba Eğitim Durumu }\end{array}$ & 0,169 & 0,762 \\
\hline Dolgu - Cinsiyet & 3,55 & 0,059 \\
\hline Dolgu - Aylık Gelir & 5,176 & 0,075 \\
\hline Dolgu - Yaşanılan Yer & 0,149 & 0,928 \\
\hline Cinsiyet - Diş Sıkma & 4,086 & 0,043 \\
\hline Diş Eksikliği - Yaşanılan Yer & 0,149 & 0,928 \\
\hline Diş Eksikliği - Aylık Gelir & 0,655 & 0,721 \\
\hline Diş Fırçalama Sıklığı - Dolgu & 7,788 & 0,379 \\
\hline
\end{tabular}

\section{BULGULAR}

Çalışmaya katılmış olan 173 öğrencinin hepsi anket formunu eksiksiz olarak doldurmuştur. Çalışmaya katılan öğrencilerin 107'si (\%62) kadın, 66’sı (\%38) erkektir (Şekil 2) ve yaş aralığı 19 ila 22 arasında değişmektedir (Şekil 3). Öğrenci ailelerinin aylık gelirleri üç ayrı aralıkta (Şekil 4), yaşam yerleri ise şehir, ilçe ve kasaba olarak (Şekil 5) sınıflandırılmıştır. Kasaba ve ilçelerde yaşamlarını sürdürmekte olan öğrencilerin restorasyon prevalansı şehirde yaşayan öğrencilerle kıyaslanmıştır. Öğrenciler, ayrıca ailelerinin eğitim durumları (Şekil 6, Şekil 7), mezun oldukları okullar (Şekil 8), sigara kullanımları, diş fırçalama ve diş ipi veya ara yüz fırçası kullanım sıklıkları, asitli içecek tüketim oranları (Şekil 9), diş hekimi ziyaretlerinin sıklığı, diş sıkma ve gece plağı kullanmaları, dolgulu ve eksik diş sayılarına (Şekil 1011) göre de sınıflandırımışlardır.

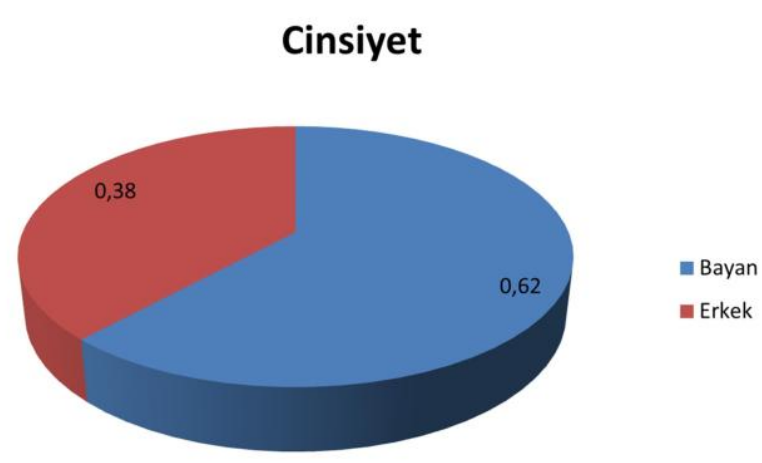

Şekil 2.

Cinsiyet grafiği

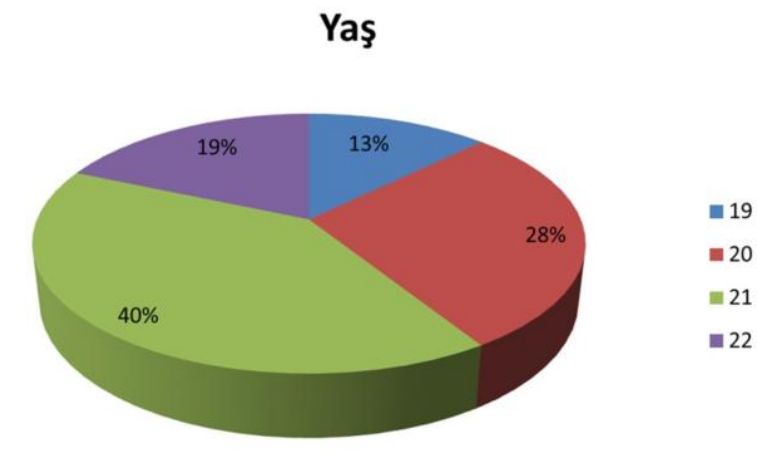

Şekil 3.

Yaş grafiği

\section{Ailenizin ortalama aylık geliri}

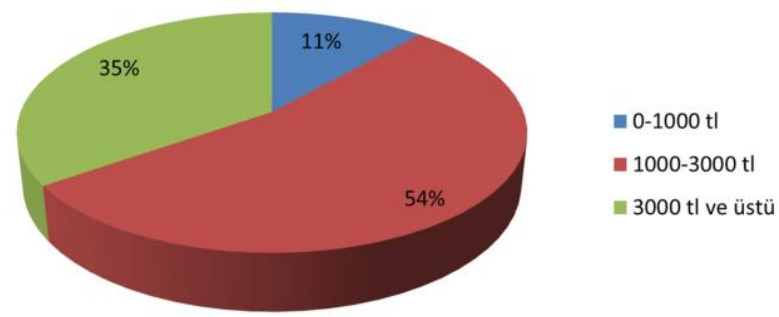

Şekil 4.

Aile ortalama aylık gelir grafiği

\section{Üniversiteden önce yaşadığınız yer}

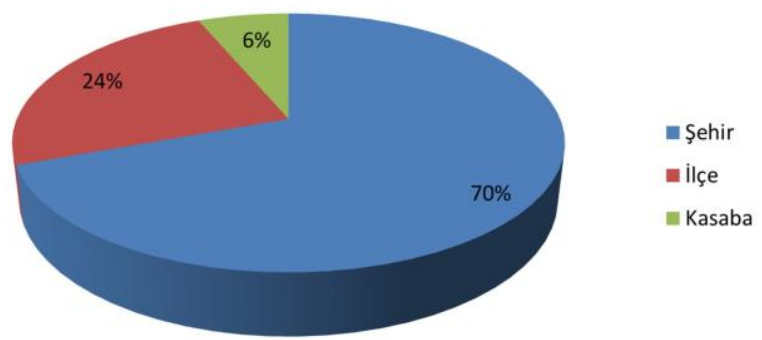

Şekil 5.

Üniversiteden önce yaşanılan yer grafiği 


\section{Baba eğitim durumu}

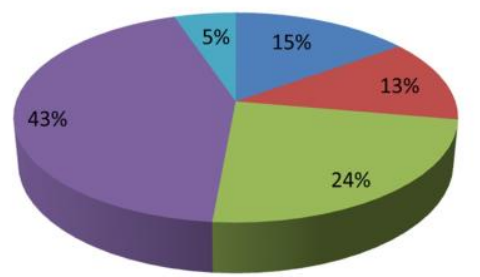
@ilkokul
mortaokul
nise
m üniversite
=yüksek lisans-doktora

Şekil 6.

Baba eğitim durumu grafiği

\section{Annenizin Eğitim Durumu}

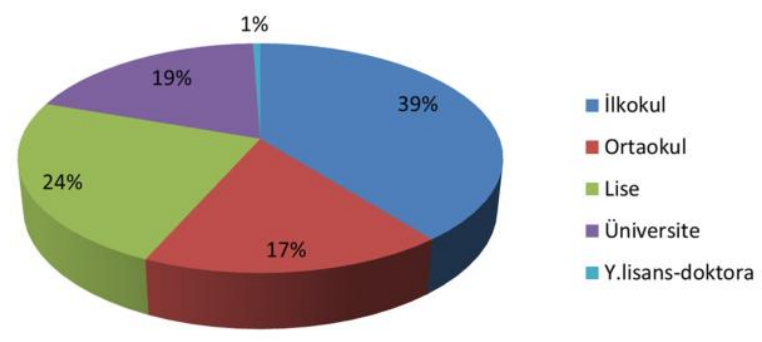

Şekil 7.

Anne eğitim durumu grafiği

\section{Mezun Olduğunuz Okul}

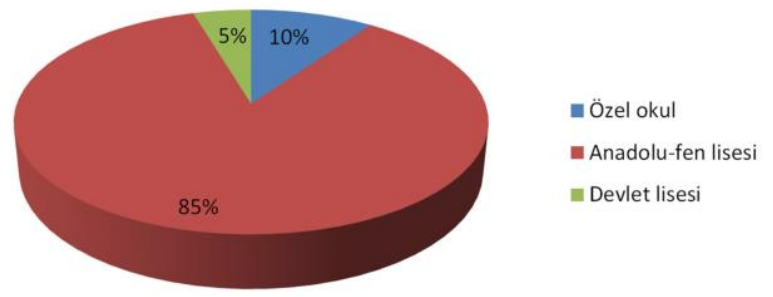

Şekil 8.

Mezun olunan okul grafiği

\section{Asitli İçecek Tüketim Oranı}

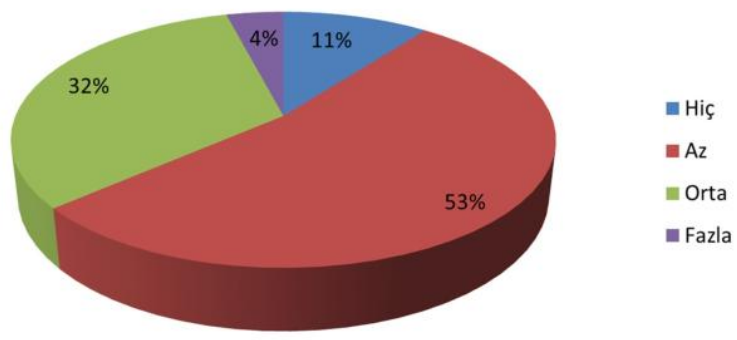

Şekil 9.

Asitli içecek tüketim oranı grafiği

\section{Ağzınızda Dolgu Var mı?}

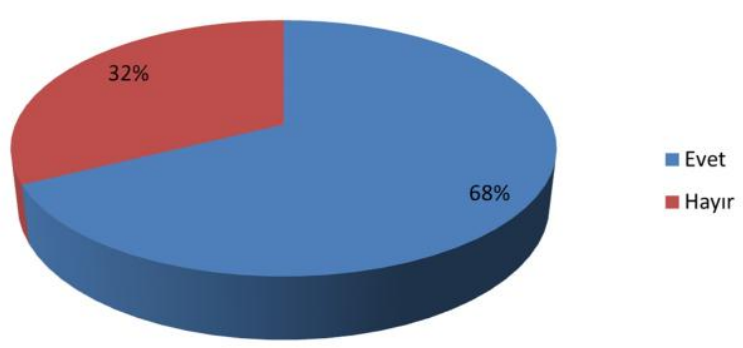

Şekil 10.

Ağızda dolgu mevcudiyeti grafiği

\section{Eksik diş}

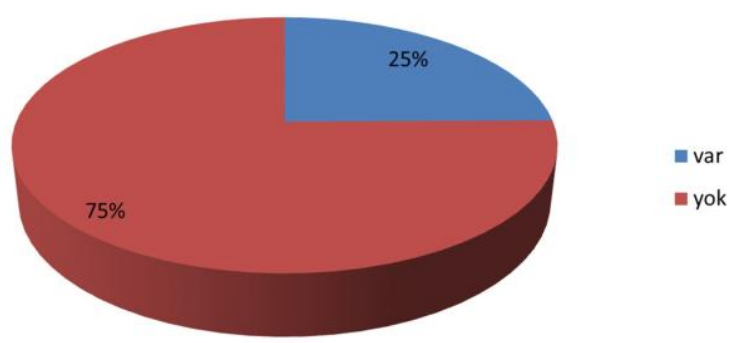

Şekil 11.

Eksik diş grafiği 
Öğrencilerin sadece 11 tanesinin protetik restorasyonu olduğu görülmüştür (Şekil 12). Yapılan ki-kare testleri sonucunda anne eğitim durumu, baba eğitim durumu ve öğrenci ailelerinin aylık gelirleri gibi faktörler ile protetik restorasyon prevelansı arasında anlamlı bir ilişki bulunmamıştır $(p>0.05)$. Bu çalışmanın ilginç sonuçlarından bir tanesi, diş hekimi endişesi taşıyan 67 öğrencinin $(\% 38,7)$ bulunmasıdır. Öğrencilerin büyük bir bölümü (\%71) dişlerini günde iki kez fırçalamaktadır (Şekil 13). Ayrıca \%56'sı diş ipi veya ara yüz fırçası kullanmaktadır (Şekil 14). Sigara içme sıklığının düşük olduğu bulunmuştur (Şekil 15). 49 öğrenci düzenli olarak diş hekimliği kontrolüne gitmektedir (Şekil 16). 69 öğrencinin diş sıkma alışkanlığı olmasına rağmen, sadece 10 öğrenci gece plağı kullanmaktadır (Şekil 17, Şekil 18).

\section{Protetik restorasyon}

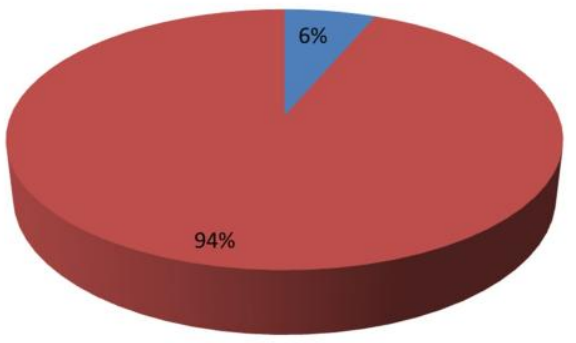

mar

myok

Şekil 12.

Protetik restorasyon mevcudiyeti grafiği

\section{Diş İpi Kullanma Sıklığı}

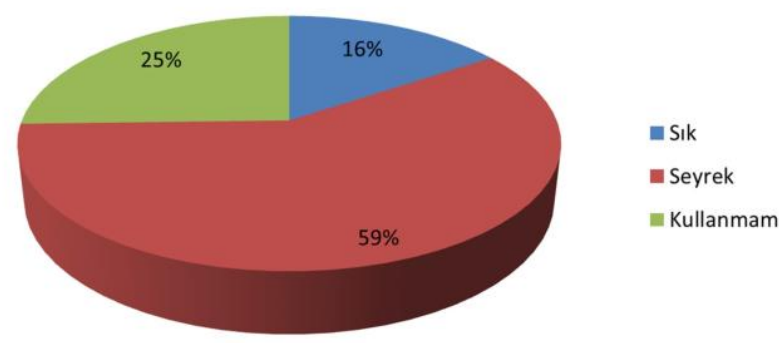

Şekil 14.

Diş ipi kullanma sıklığı grafiği

\section{Sigara Kullanma Sıklığı}

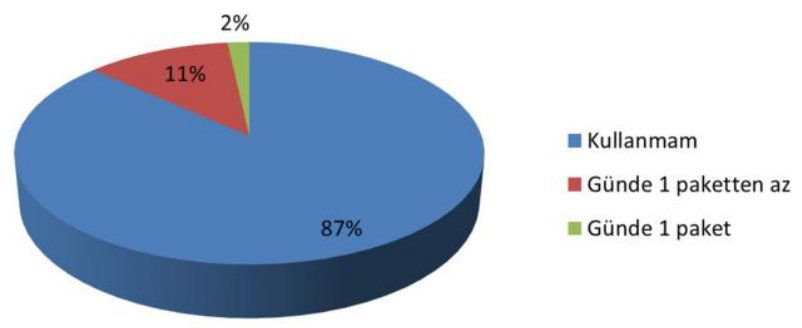

Şekil 15.

Sigara kullanma sıklığı grafiği

\section{Diş Hekimi Kontrolüne Gitme Sıklığı}

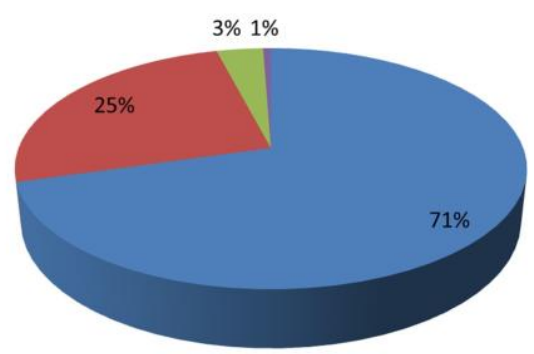

n Günde 2 kez

n Günde $1 \mathrm{kez}$

m Seyrek

घ Hiç fırçalamam

Şekil 13.

Diş firçalama sıklığı grafiği

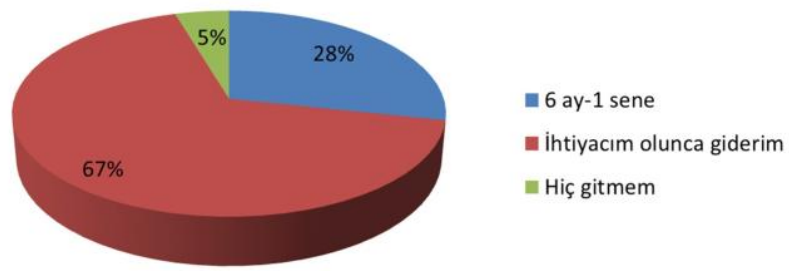

Şekil 16.

Diş hekimi kontrolüne gitme sıklığı grafiğgi 


\section{Diş Sıkma Alışkanlığınız Var mı?}

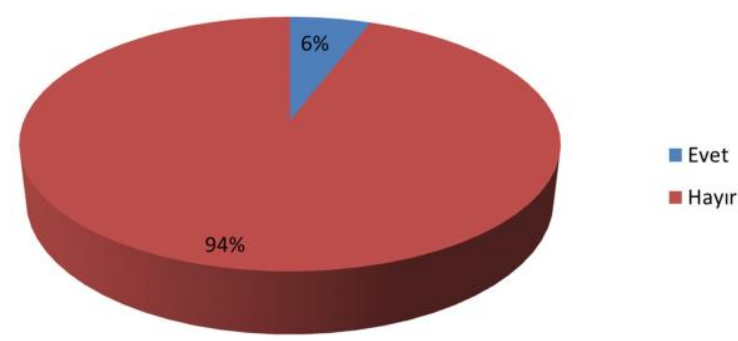

Şekil 17.

Diş sıkma alışkanlı̆̆ grafiği

\section{Gece Plağı Kullanıyor musunuz?}

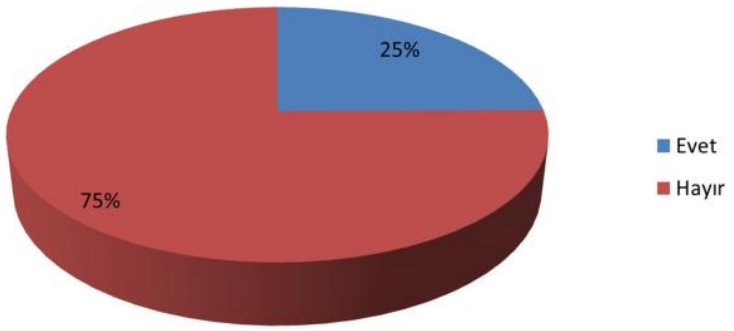

Şekil 18.

Gece plağı kullanımı grafiği

Öğrencilerin dolgulu dişleri incelendiğinde kız öğrencilerin dolgu prevelansının $(\% 72,8)$ erkek öğrencilerin dolgu prevelansından yüksek olduğu $(\% 59,1)$ görülmüştür; ancak istatistiksel olarak anlamlı bir fark bulunmamıştır $(p>0.05)$. Ailelerinin aylık geliri 3000 TL üzeri olan öğrencilerin dolgu prevelansı $(\% 56,7)$, düşük $(\% 70)$ ve orta $(\% 74,2)$ gelirli ailelere sahip öğrencilere göre daha düşük bulunmuştur. Üniversiteden önce şehirde yaşayan öğrencilerin \%67,5'i dolgu yaptırmışken üniversiteden önce kasabada yaşayan öğrencilerin $\% 72,7$ 'si dolgu yaptırmıştır. İstatistiksel inceleme sonucu üniversite öncesi yaşanılan yer ile öğrencilerin dolgu yaptırmaları arasında anlamlı bir ilişki bulunmamıştır $(p>0.05)$.

Öğrencilerin diş sıkma alışkanlıkları incelendiğinde kız öğrencilerin erkek öğrencilere göre daha fazla diş sıktığı istatistiksel olarak ortaya konmuştur $(p<0.05)$. Kız öğrencilerin \%45,8'i erkek öğrencilerin ise $\% 30,3$ 'ü diş sıkmaktadır. Öğrenci ailelerinin gelirleri ile öğrencilerin diş sıkmaları arasındaki ilişkide istatistiksel olarak anlamlı bir ilişkiden söz etmek mümkün değildir ( $p>0.05)$; ancak ailelerin gelirleri arttıkça yüzdesel olarak diş sıkmada azalma gözlemlenmiştir.

Üniversite eğitimine başlamadan önce şehirde yaşayanların \%20'sinin diş eksikliği bulunurken üniversiteden önce ilçede yaşayanların \%35,7'sinin, üniversiteden önce kasabada yaşayanların ise \%36,4'ünün diş eksikliği olduğu görülmüştür. Benzer şekilde aylık gelirin artması da diş eksikliğinde yüzdesel olarak değişime neden olmuştur. Aylık geliri 0-1000 TL arasında olanların \%30'unun, 1000-3000 TL arasında olanların \%25,8'inin, $3000 \mathrm{TL}$ ve üzeri olanların $\% 21,7$ 'sinin diş eksikliği bulunmaktadır. Yapılan ki kare testleri sonucunda iki veri için de istatistiksel olarak anlamlı bir fark bulunmazken $(p>0.05)$, değişken sosyoekonomik faktörler etkilerini yüzdesel olarak göstermiştir.

Öğrencilerin diş fırçalama sıklıkları ile dolgu prevelansları arasındaki ilişkiye bakıldığında dişlerini günde 2 kez firçalayan öğrenciler ile günde $1 \mathrm{kez}$ veya daha seyrek fırçalayan öğrencilerin dolgu prevelansları arasında istatistiksel açıdan önemli bir fark bulunmamıştır $(p>0.05)$.

\section{TARTIŞMA}

$\mathrm{Bu}$ çalışmada, Selçuk Üniversitesi Diş Hekimliği Fakültesindeki preklinik öğrencilerinin sosyoekonomik koşulları ile ağız sağıkları ve oral hijyen alışkanlıkları arasındaki ilişki değerlendirilmiştir. Topluluklar üzerine yapılan çalışmaların sosyoekonomik farklılıkların etkisini tam anlamılla ortaya koyması zordur. Bu nedenle, sosyoekonomik değişkenlerin etkisi hakkında fikir sahibi olabilmek için dikkatli bir inceleme gerekmektedir. ${ }^{20}$ Gelir, eğitim, sosyal konum ve yaşanılan bölge gibi faktörlerin ağız sağlığı üzerinde etkisi olduğuna dair bilgiler mevcuttur; ancak bugüne kadar elde edilen veriler çelişkilidir. ${ }^{21-25}$ Gelir, sağlık hizmetlerinin karşılanabilmesine olanak sağlar ve bu nedenle ağız sağlığı üzerine ömür boyu sonuçları olan klinik kararları etkilemektedir. Eğitim ise sunulan hizmetlerin değerlendirmesi ve bilginin kullanması adına önem taşımaktadır.

Dünya genelinde yapılan benzer çalışmalar, ${ }^{26,27}$ düşük sosyoekonomik statünün çeşitli ağız hastalıklarına ve oral hijyen alışkanlıklarına olan etkilerini belgelemiştir. Oral hijyen alışkanlıklarının yetersizliği, diş çürüğü, kanal tedavisi intiyacı veya diş çekimi gibi sonuçları beraberinde getirmektedir. Sosyoekonomik seviye ile çürük arasındaki ilişki genellikle 7-12 yaş arası çocuklarda yapılan araştırmalar sonucu tanımlanmıştır ve sosyoekonomik statüsü yüksek olan ailelerin çocuklarında görülen çürük oranının, sosyoekonomik seviyesi düşük olan ailelerin çocuklarında görülen çürük oranından daha az olduğu rapor edilmiştir. ${ }^{28-30} \mathrm{Bu}$ 
nedenle geçmiş yıllardaki çalışmalar temel alındığında oral hijyen alışkanlıklarının sosyoekonomik statü ile ilişkili olduğunu söylemek mümkündür. Bu çalışmada diş fırçalama sıklığı ile dolgu prevelansı arasındaki ilişkinin önceki çalışmalardan farklı olması, incelenilen topluluğun diş hekimliği öğrencilerinden oluşmasından kaynaklanabilir.

Üniversite öğrencileri arasında yapılan çalışmalar stres düzeyinde cinsiyet farkının varlığını ortaya koymakta ve stresin kIz öğrenciler için daha yüksek olduğunu bildirmektedir. ${ }^{31-34} \mathrm{Bu}$ çalışmada diş sıkma prevelansları karşılaştııılığında kız öğrencilerin diş sıkma oranının erkek öğrencilere göre daha fazla olduğu görülmektedir. $\mathrm{K} ı \mathrm{z}$ öğrencilerdeki yüksek diş sıkma oranı psikolojik baskı ve beklentilerin yüksek olması kaynaklı ortaya çıkan stres ile ilişkilendirilebilir. ${ }^{35}$

Diş eksikliği, fonksiyon kaybına bağlı olarak çiğneme zorlukları ve beslenmede önemi olan bazı gıdalardan kaçınmak gibi sonuçlar doğurmaktadır. ${ }^{36}$ Buna bağlı olarak bireylerin ağız ve diş sağlığı yanında genel sağlığını da etkileyebilecek durumlar ortaya çıkabilir. Kaybedilen dişlerin yerine konması veya ciddi derecede defektli dişlerin tedavisi noktasında kron, köprü, implant üstü, inley ve onley restorasyonlar gibi protetik çözümler devreye girmektedir, ancak bu restoratif çözümlerin prevelansı daha ileri yaş grubundaki hastalarda artmaktadır. Bu nedenden dolayı çalışmadaki protetik restorasyon $(\% 6,4)$ ve eksik diş $(\% 25)$ prevelansı düşük olarak bulunmuştur.

Bu çalışma sonucu elde edilen veriler sosyoekonomik faktörlerin ağız sağığına olan etkilerinin basit ve kesin yargılar ile ortaya konmasının zor olduğunu göstermiştir. Bunun nedeni ise araştırılan nüfus ve bu nüfusa yöneltilen sorulardır. Çalışmaya katılmıs olan topluluğun diş hekimliği öğrencileri tarafından oluşturulmuş olması hem ağız sağlığına hem de oral hijyen uygulamalarına olan yatkınlığın yüksek olduğu bir popülasyon oluşmasına sebep olmuştur. Bu sebepten dolayı elde edilen veriler geçmiş çalışmalarda elde edilen veriler ile ayrılık göstermektedir. Sosyoekonomik faktörlerin ağız sağlığı üzerine olan etkilerinin tam olarak anlaşılabilmesi için farklı popülasyonlarda ve birey sayısının arttırıldığı ilave çalışmalara intiyaç duyulmaktadır.

\section{SONUÇ}

Birçok faktör ağız sağlığını etkileyebilmektedir. Bu çalışmada sosyoekonomik durumun Selçuk Üniversitesi Diş Hekimliği Fakültesi öğrencilerinin ağız sağlığı üzerinde istatiksel olarak önemsiz bir etkisi olduğu gözlemlenmiştir. 


\section{KAYNAKLAR}

1. Park JB, Han K, Park YG, Ko Y. Association between socioeconomic status and oral health behaviors: The 2008-2010 Korea national health and nutrition examination survey. Exp Ther Med 2016; 12: 2657-64.

2. Jin LJ, Lamster IB, Greenspan JS, Pitts NB, Scully C, Warnakulasuriya $S$. Global burden of oral diseases: Emerging concepts, management and interplay with systemic health. Oral Dis 2016; 22: 609-19.

3. Linden GJ, Lyons A, Scannapieco FA. Periodontal systemic associations: Review of the evidence. J Clin Periodontol 2013; 40: S8-19.

4. Macintyre S. Understanding the social patterning of health: the role of the social sciences. J Public Health Med 1994; 16: 53-9.

5. Marmot MG, Smith GD, Stansfeld S, Patel C, North F, Head J, White I, Brunner E, Feeney A. Health inequalities among British civil servants: the Whitehall II study. Lancet 1991; 337: 138793.

6. Matthews KA, Gallo LC. Psychological perspectives on pathways linking socioeconomic status and physical health. Annu Rev Psychol 2011; 62: 501-30.

7. Dasgupta $P$, Weale $M$. On measuring the quality of life. World Development 1992; 20: 119-31.

8. Thomson WM. Social inequality in oral health. Community Dent Oral Epidemiol 2012; 40: 2832.

9. Loe $\mathrm{H}$. Oral hygiene in the prevention of caries and periodontal disease. Int Dent J 2000; 50: 129-39.

10.Touger-Decker $R$, van Loveren C. Sugars and dental caries. Am J Clin Nutr 2003: 78; 881-892.

11. Sharda AJ, Shetty S. A comparative study of oral health knowledge, attitude and behaviour of first and final year dental students of Udaipur city, Rajasthan, India. Int J Dent Hyg 2008: 6; 347-53.

12. Kassak KM, Dagher R, Doughan B. Oral hygiene and lifestyle correlates among new undergraduate university students in Lebanon. J Am Coll Health 2001; 50: 15-20.

13. Kirtiloğlu T, Yavuz US. An assessment of oral self-care in the student population of a Turkish university. Public Health 2006; 120: 953-7.

14.Rimondini L, Zolfanelli B, Bernardi F, Bez C. Selfpreventive oral behavior in an Italian university student population. J Clin Periodontol 2001; 28: 207-11.

15.Luebke TE, Driskell JA. A group of Midwestern university students needs to improve their oral hygiene and sugar/pop consumption habits. Nutr Res 2010; 30: 27-31.
16.Chindia ML, Valderhaug J, Ng'ang'a PM. Oral health habits and periodontal health among a group of university students in Kenya. East Afr Med J 1992; 69: 337-40.

17. Bamise CT, Bada TA, Bamise FO, Ogunbodede EO. Dental care utilization and satisfaction of residential university students. Libyan J Med 2008; 3: 20-25.

18. Neamatollahi H, Ebrahimi M. Oral health behavior and its determinants in a group of Iranian students. Indian J Dent Res 2010; 21: 84-8.

19.Ventä I, Murtomaa H, Meurman J, Turtola L. Use of dental services by students of Helsinki University during six years. Proc Finn Dent Soc Suom Hammaslaakariseuran Toim 1992; 88: 123-9.

20.Steele J, Shen J, Tsakos G, Fuller E, Morris S, Watt R, Guarnizo-Herreño C, Wildman J. The Interplay between Socioeconomic Inequalities and Clinical Oral Health. J Dent Res 2015; 94: 19-26.

21. Lopez R, Fernandez O, Baelum V. Social gradients in periodontal diseases among adolescents. Community Dent Oral Epidemiol 2006; 34: 184-96.

22.Turrell G, Sanders AE, Slade GD, Spencer AJ, Marcenes $W$. The independent contribution of neighborhood disadvantage and individual-level socioeconomic position to self-reported oral health: a multilevel analysis. Community Dent Oral Epidemiol 2007; 35: 195-206.

23.Celeste RK, Nadanovsky P, Ponce de Leon A, Fritzell $\mathrm{J}$. The individual and contextual pathways between oral health and income inequality in Brazilian adolescents and adults. Soc Sci Med 2009; 69: 1468-75.

24. Borrell LN, Baquero MC. Self-rated general and oral health in New York City adults: assessing the effect of individual and neighborhood social factors. Community Dent Oral Epidemiol 2011; 39: 361-71.

25. Shen J, Wildman J, Steele J. Measuring and decomposing oral health inequalities in a UK population. Community Dent Oral Epidemiol 2013; 41: 481-9.

26. Segovia-Villanueva A, Estrella-Rodriguez $R$, Medina-Solis CE, Maupomé G. Dental caries experience and factors among preschoolers in Southeastern Mexico. J Public Health Dent 2006; 66: 88-91.

27. Maupomé G. An introspective qualitative report on dietary patterns and elevated levels of dental decay in a deprived urban population in northern Mexico. ASDC J Dent Child 1998; 65: 276-85.

28.Tulunoğlu Ö, Bodur $H$, Ulusu $T$, Ciğer R, Odabaş M. Okul öncesi (3-6 yaş) ve okul çağındaki (7-12 yaş) çocuklarda diş yüzeylerindeki çürük dağıımının ve prevalansının karşılaştırmalı olarak değerlendirilmesi. GÜ Diş Hek Fak Derg 2003; 20: 11-6. 
29. Wierzbicka M, Petersen PE, Szatko F, Dybizbanska $\mathrm{E}$, Kalo I. Changing oral health status and oral health behaviour of school children in Poland. Community Dent Health 2002; 19: 243-50.

30. Eronat N, Ertuğrul F, Uğur ZA, Önçağ Ö, Köse T. İzmir Bornova'da sosyoekonomik düzey ile ağız diş sağlığı durumunun 7 ve 12 yaş grubu çocuklarda değerlendirilmesi. HÜ Diş Hek Fak Derg 1997; 21: 46-51.

31.Ahlberg J, Rantala M, Savolainen A, Suvinen T, Nissinen M, Sarna $S$ et al. Reported bruxism and stress experience. Community Dent Oral Epidemiol 2002; 30: 405-8.

32. Mikolajczyk RT, El Ansari W, Maxwell AE. Food consumption frequency and perceived stress and depressive symptoms among students in three European countries. Nutr J 2009; 8: 31.

33.Shah M, Hasan S, Malik S, Sreeramareddy C. Perceived stress, sources and severity of stress among medical undergraduates in a Pakistani medical school. BMC Med Educ 2010; 10: 2.

34.Dahlin M, Joneborg N, Runeson B. Stress and depression among medical students: a cross sectional study. Med Educ 2005; 39: 594-604.

35. Cavallo P, Carpinelli L, Savarese G. Perceived stress and bruxism in university students. BMC Res Notes 2016; 9: 514.

36. Moynihan P, Bradburj J. Compromised dental function and nutrition. Nutrition 2001; 17: 177-8.

Yazışma Adresi:

Doç.Dr.Münir Tolga YÜCEL

Selçuk Üniversitesi

Diş Hekimliği Fakültesi

Protetik Diş Tedavisi AD

Konya, Türkiye

Tel : +90 3322231194

Faks : +90 3322410062

E-mail: munirtolga@selcuk.edu.tr 